\title{
Experience of Using Total Station and GNSS Technologies for Tall Building Construction Monitoring
}

\author{
Irineu da Silva ${ }^{1(\bowtie)}$, Wernher Ibañez ${ }^{2}$, and Guilherme Poleszuk ${ }^{1}$ \\ 1 Department of Transportation Engineering, \\ School of Civil Engineering of São Carlos, \\ University of São Paulo, São Carlos, Brazil \\ irineu@sc.usp.br, guilherme.poleszuk@usp.br \\ ${ }^{2}$ Escuela de Ingeniería Eléctrica, Universidad Católica de Valparaíso, \\ Santiago, Chile \\ wibanezl@gmail.com
}

\begin{abstract}
In prevalent engineering practice, geodetic measurement techniques are commonly applied for structural monitoring. For a long time, triangulation, trilateration and levelling techniques have been trusted for the determination of structural deformation and point displacement, with excellent outcomes. With the advent of robotic total stations, the three-dimensional topographic measurement method has been proposed as an efficient and rapid measurement option for the determination of 3D coordinates. In addition, the GNSS (Global Navigation Satellite System) technology improvements, mainly in the RTK (Real-Time Kinematic) measurement mode, opened a new perspective for monitoring, which has also shown consistent results. However, there are some situations where the use of total station or GNSS technology individually is not enough to perform the monitoring. The solution may then be the combination of both technologies. In this paper, we present the details of two proposed measurement methods and the results of a testing campaign carried out to monitor the construction of "La Costanera Tower", in Santiago, Chile, using a total station combined with GNSS receivers. These methods are based on the use of GNSS antennas and total station installed on the under-construction building floor. Having this scenario, two measurement procedures were applied. The first one was based on using a total station coupled with a GNSS receiver, for determining the position of the monitoring point and a GNSS antenna coupled with prism reflector, for the orientation of the total station. The second procedure was based on using a total station and two GNSS antennas coupled with prism reflectors. With this equipment, directions and distances were measured, to determine the position and orientation of the total station, by means of a Free Station positioning computation. The testing results have been compared with traditional measurement techniques. The results showed that the proposed methods could be a suitable solution for monitoring tall building construction.
\end{abstract}

Keywords: Geodetic monitoring - Tall building monitoring · GNSS · Total station · Free Station · Polar measurement 


\section{Introduction}

Structural monitoring by using geodetic methods is an engineering practice, that is already very well established in the technical and scientific community. For a long time, it has relied on triangulation, trilateration and levelling techniques for the determination of structural deformation and point displacement with excellent results, as seen in US Army Corps of Engineers (2002) and Bird (2009). Recently, with the arrival of robotic total stations, the three-dimensional topographic measurement method has been proposed as a faster measurement option for this type of work, as described in Beshr and Kaloop (2013). Installation facilities based on this method are found in many applications of geodetic monitoring, especially those related to mining and construction of large structures, as shown in Afeni and Cawood (2013). Several application programs based on these geodetic measuring methods are commercially available and have been used successfully, such as GeoMoS from Leica Geosystems, among others. With the improvement of GNSS technology, in both post-processing and RTK modes, it opened up a new perspective for structural monitoring, which has also shown consistent results in the analysis of deformations and displacements, as shown in Yi et al. (2012). However, there are some situations where the use of total stations or GNSS technology alone is not enough to perform the proposed monitoring. A typical example of such a situation is the monitoring with total station in areas where the control points cannot be installed outside the area of influence of the structural displacement, such as, in some cases of slope monitoring of open pit mines. In the case of monitoring with GNSS technology, the difficulty of installing the GNSS antenna at all points of the monitored structure is a typical issue, thus requiring the complementation with total stations and prism reflectors. In such cases the solution is the combination of both technologies - GNSS and total station measurements, as shown in Van Cranembroeck (2011).

This article presents the results of the structural monitoring test carried out during the construction of "La Costanera Tower", in the city of Santiago, Chile - the tallest building ever built in Latin America. Due to this fact, to ensure the verticality of the building and to monitor its movements, the builders conducted tests with different monitoring methods, among which stood out the use of electronic inclinometers and geodetic monitoring techniques. Regarding the latter, three methods of measurements with installations of instruments on the under-construction floor were tested because some monitoring points of the building could not be sighted from ground stations. The methods include: $(i)$ Free Station positioning method, based on the use of a total station, installed on the under-construction floor, and strategically installed landmarks in the terrain, surrounding the construction area of the building. (ii) Polar measuring method, based on the use of a total station coupled with GNSS receiver, to determine the instrument position, and one GNSS antenna coupled with a prism reflector, for the orientation of the total station, both installed on the under-construction floor. (iii) Free Station positioning method, based on the use of a total station and two GNSS antennas, coupled with prism reflectors installed on the under-construction floor. 


\section{La Costanera Tower}

The construction of "La Costanera Tower" was started in 2004. It is a commercial building, with a shopping mall on its lower floors and commercial spaces on the upper floors. The structure of the building is of reinforced concrete, supported by a central rigid nucleus formed by columns and beams, around which the architectural structures are constructed. See Fig. 1. The building has a total height of $300 \mathrm{~m}$, with a base area of $50 \mathrm{~m} \times 50 \mathrm{~m}$. The central rigid nucleus has an area of $26.8 \mathrm{~m} \times 24.6 \mathrm{~m}$.

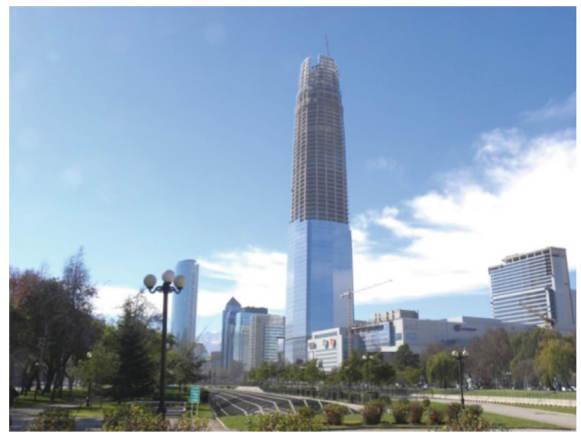

a. General view of the building.

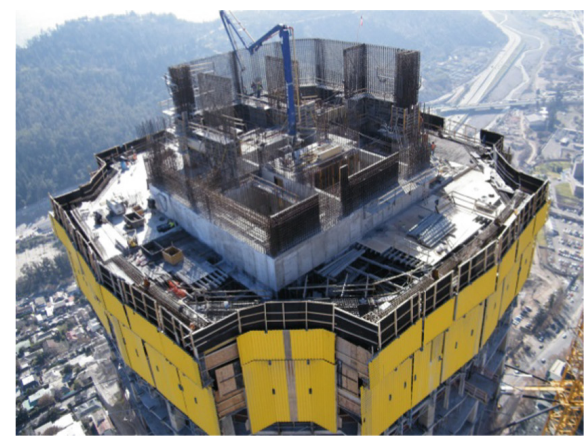

b. View of the central rigid nucleus.

Fig. 1. Images of La Costanera Tower in its final construction phase.

The two main reasons for the construction monitoring of "La Costanera Tower" were: to investigate the structural behaviour, when stressed out by wind action and to control the construction verticality. As the building grew vertical, it provided more area for wind exposure. From the structural point of view, the wind "pushes" the building and this action deforms it in the direction of the wind. However, it occurs for tall buildings, the wind rounds the building, generating a rhythmic force perpendicular to the wind, causing the building to oscillate dynamically, generating discomfort to users. To better understand this effect, a model of the building was fabricated, in a scale of 1:400, which was required for simulation purpose in wind tunnel. The simulation results, guided the structural design and the construction of the building.

Although the structural behaviour of the building has been evaluated in detail by means of simulation in the wind tunnel, it was considered prudent to monitor its movements and deformations to ensure the validity of the structural model and the verticality of the building. For this purpose, the builders proposed, use of various monitoring methods, including the concept of geodetic monitoring, by integrating polar measurement techniques with total stations and GNSS technology, as described in this text.

\section{Instruments}

The surveying instruments for this testing are presented in Tables 1 and 2 . 
Table 1. Surveying instrument for Polar measurements.

\begin{tabular}{l|l}
\hline Instrument & 1 robotic total station: model TCRA1201-R300 \\
\hline Angular accuracy & $1.0 "$ \\
\hline Linear accuracy & $1 \mathrm{~mm}+1 \mathrm{ppm}$ \\
\hline Range & $2.8 \mathrm{~km}$ (normal conditions) \\
\hline Tracking method & ATR and signal returning \\
\hline
\end{tabular}

Table 2. GNSS instruments.

\begin{tabular}{l|l}
\hline Instrument & $\begin{array}{l}\text { 1 GNSS receiver, model GRX1200, 2 GNSS receivers, model } \\
\text { GX1230Plus and 1 GNSS receiver, model ATX1230 }\end{array}$ \\
\hline Channels & 120 channels L1 e L2, GLONASS \\
\hline Linear accuracy & $3 \mathrm{~mm}+0.5 \mathrm{ppm}$ \\
\hline $\begin{array}{l}\text { Position } \\
\text { accuracy }\end{array}$ & $10 \mathrm{~mm}+0.5 \mathrm{ppm}$ \\
\hline $\begin{array}{l}\text { Measurement } \\
\text { range }\end{array}$ & $30 \mathrm{~km} \mathrm{RTK},>30 \mathrm{~km}$ post-processing \\
\hline Position rate & $20 \mathrm{~Hz}$ \\
\hline
\end{tabular}

As shown in Tables 1 and 2, one total station and four GNSS receivers were employed. The first GNSS receiver was installed as a base station for the GNSS system. The second GNSS receiver was coupled with the total station, as shown in Fig. 2a. The third and fourth GNSS antennas were coupled with $360^{\circ}$ prism reflectors forming two sets of back points (orientation points), as shown in Fig. 2b.

\section{Monitoring Methodology and Testing Objective}

The relevance of the test for the geodetic monitoring of "La Costanera Tower" using total stations and GNSS receivers resided in the fact that there was a need to monitor the central building nucleus. As it is located in the center of the building, after a certain height, it was important to consider that not all the monitoring points would be monitored through the reference points located on the ground and neither by GNSS antennas installed on the structural frame, due to the problems of satellite signals reception. For this reason, an appropriate solution was to perform an alternative measurement, designed using total station and GNSS receivers. The equipment worked closely after it was installed on the under-construction floor. As already mentioned, the test was conducted with the application of three measurement methods in accordance with the procedures indicated below:

(a) Measurement with total station, installed on the under-construction floor and prism reflectors, installed on reference points deployed on the ground. This is a conventional measurement method, which was considered as a reference to the other ones.

(b) Measurement with total station coupled with a GNSS receiver and prism reflectors, installed on the under-construction floor. 


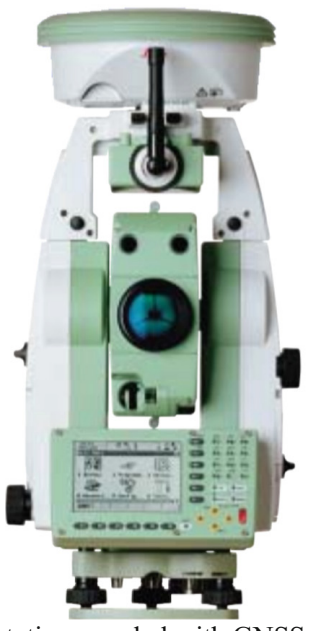

a. Total station coupled with GNSS receiver.

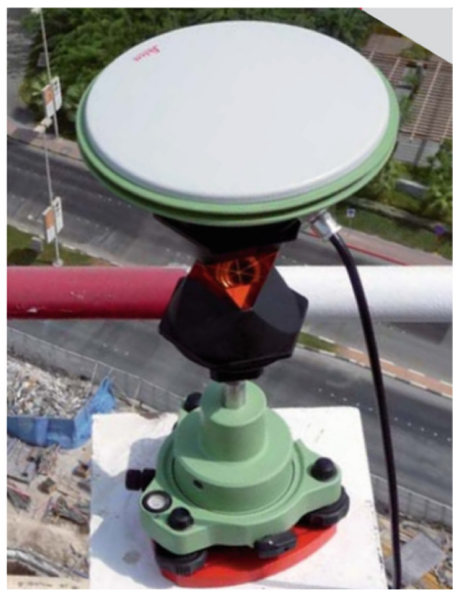

b. GNSS antenna coupled with $360^{\circ}$ prism reflector.

Fig. 2. Total station and a prism reflector coupled with GNSS receiver and GNSS antenna.

(c) Measurement with total station and prism reflectors coupled with GNSS antennas, installed on the under-construction floor.

The objectives of the tests conducted are as following:

1. To check the consistency between the results obtained with polar measurements, through total station and prism reflectors, and the results obtained by combining GNSS and total station measurements.

2. To check if the methodology of coupling total station with GNSS receivers maintains the levels of accuracies achieved with measurements through GNSS technology, in RTK mode.

3. To establish an operational routine based on the obtained results.

To achieve the objectives mentioned above, the geometry of the measurement was based on: (i) installation of a GNSS receiver called (E1) on a control point to operate as base station, (ii) installation of two prism reflectors coupled with GNSS antennas called (E2) and (E3), on the under-construction floor and (iii) installation of a total station coupled with the GNSS receiver called (E4) on a pillar, anchored on the floor under construction, in solidarity with the central nucleus of the building. From the station (E4), the coordinates of two monitoring points (P1) and (P2) were determined (as shown in Fig. 3).

The first step of taking measurements was to install the total station over a forced centring pillar, targeting three control points on the ground, calculating its coordinates by Free Station positioning method, aiming the two monitoring points (P1) and (P2) and calculating their coordinates by Polar measurement method. The coordinate values obtained by this process were adopted as reference coordinates (true values). The second step of the measurements was to determine the coordinates of the total station 


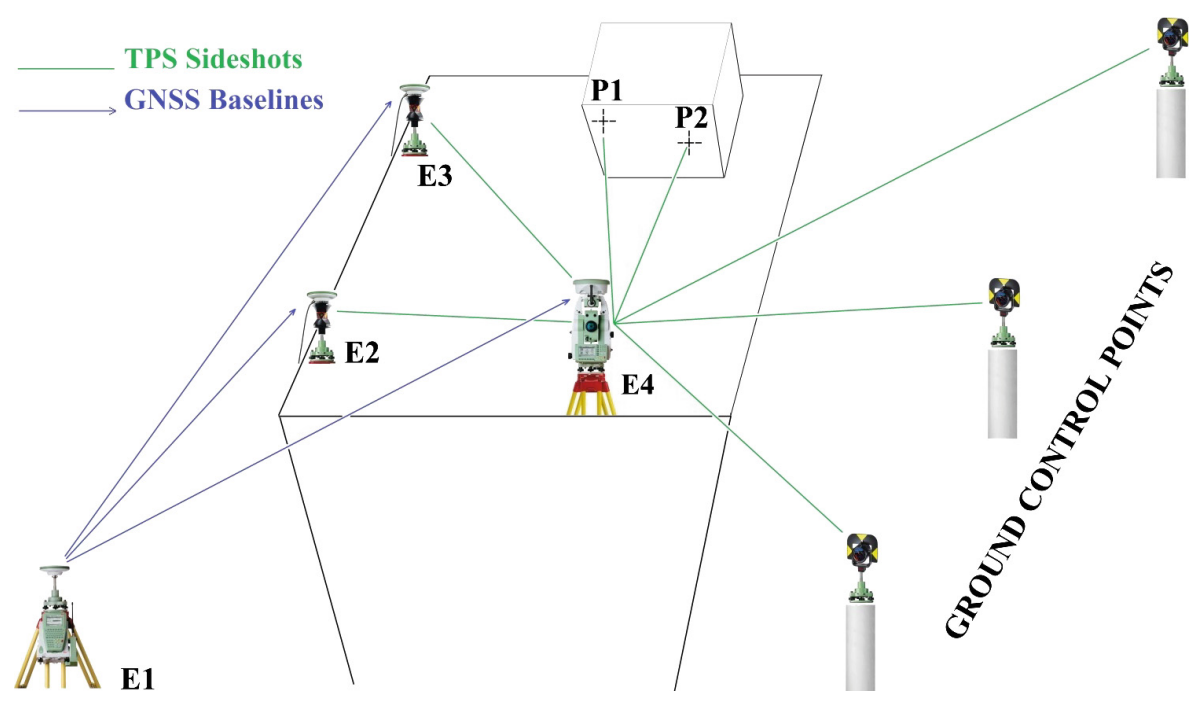

Fig. 3. Measurement geometry.

by means of the GNSS receiver, coupled with the total station and orienting the measurement system backing to one of the prism reflectors coupled with GNSS antenna - (E2) or (E3), whose coordinates were computed by GNSS post-processing mode. The coordinates of points (P1) and (P2) were determined afterwards by Polar measurement method. The third step of the measurements was to determine the coordinates of the total station through the Free Station positioning method, aiming the points (E2) and (E3), whose coordinates were determined by the GNSS antennas, in RTK mode. Then, aiming the monitoring points (P1) and (P2), for calculation of coordinates by the Polar measurement method.

The consistency of measurement methods has been proven by comparing the results obtained from of the second and third method of measurements with the results of the first one.

\subsection{Polar Method}

The Polar Method is a conventional surveying method for determining spatial coordinates of points based on the measurement of horizontal directions, vertical angles and slope distances. By setting up a total station at a known point $\left(\mathrm{X}_{\mathrm{S}}, \mathrm{Y}_{\mathrm{S}}, \mathrm{H}_{\mathrm{S}}\right)$ and referencing it to another known point $\left(\mathrm{X}_{\mathrm{R}}, \mathrm{Y}_{\mathrm{R}}, \mathrm{H}_{\mathrm{R}}\right)$, as indicated in Fig. 4, it is possible to determine the spatial coordinates $\left(\mathrm{X}_{\mathrm{P}}, \mathrm{Y}_{\mathrm{P}}, \mathrm{H}_{\mathrm{P}}\right)$ of any survey point, aimed from that total station. The spatial coordinates are computed as following:

$$
X_{P}=X_{S}+d_{S P}^{\prime} * \operatorname{sen}\left(z_{S P}\right) * \operatorname{sen}\left(\varphi_{S P}\right)
$$




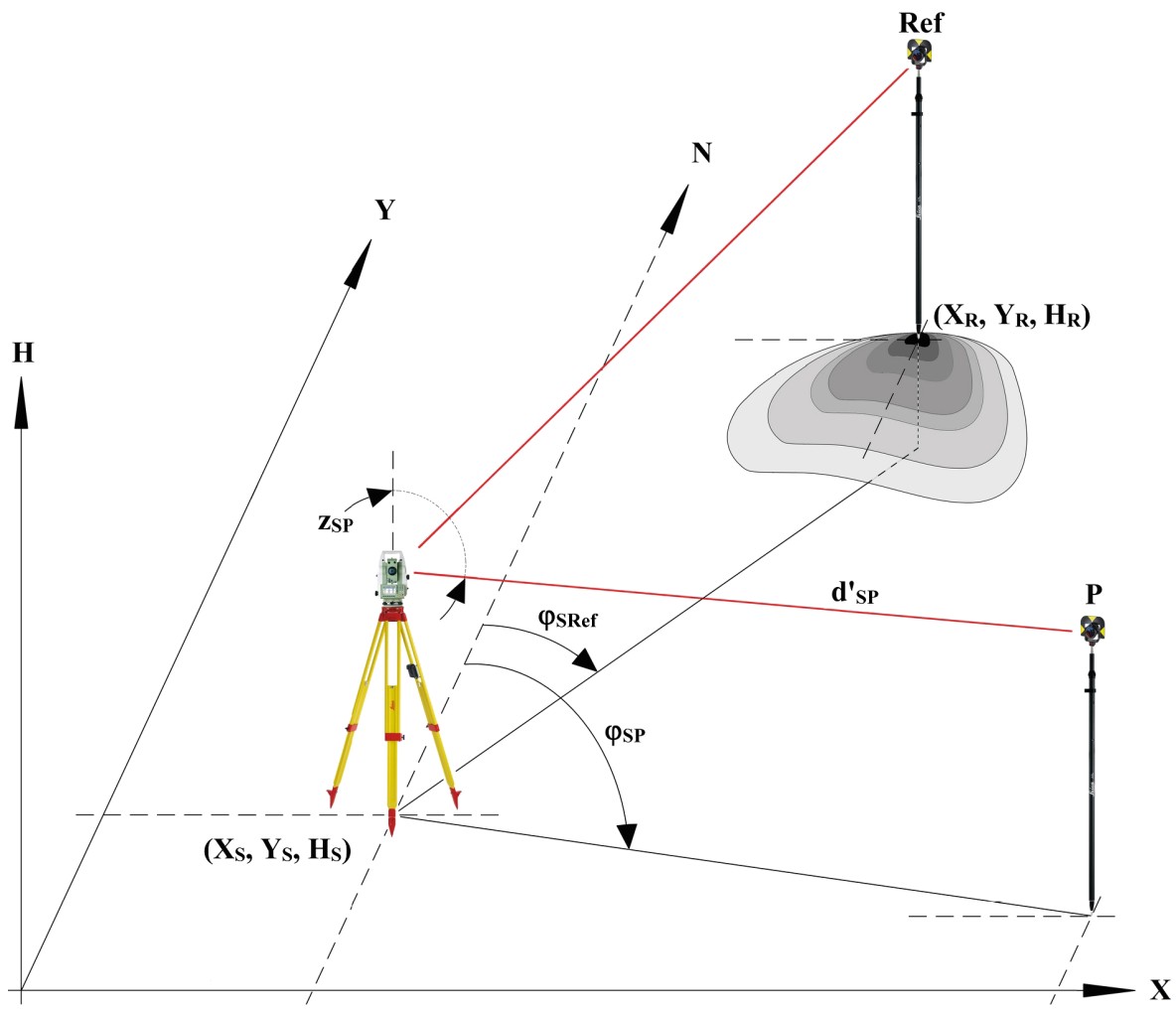

Fig. 4. Polar measurement method.

$$
\begin{gathered}
Y_{P}=Y_{S}+d_{S P}^{\prime} * \operatorname{sen}\left(z_{S P}\right) * \cos \left(\varphi_{S P}\right) \\
H_{P}=H_{S}+d_{S P}^{\prime} * \cos \left(z_{S P}\right)+h_{i}-h_{r} \\
\varphi_{S P}=\operatorname{arctg} \frac{X_{R}-X_{S}}{Y_{R}-Y_{S}}
\end{gathered}
$$

Where,

$X_{S}, Y_{S}, H_{S}=$ coordinates of station point (S)

$X_{P}, Y_{P}, H_{P}=$ coordinates of survey point $(\mathrm{P})$

$d_{S P}^{\prime}=$ slope distance from point $(\mathrm{S})$ to point $(\mathrm{P})$

$z_{S P}=$ vertical angle at station $(\mathrm{S})$

$\varphi_{S P}=$ horizontal direction from point $(\mathrm{S})$ to point $(\mathrm{P})$

$h_{i}=$ instrument height at station (S)

$h_{r}=$ reflector height at point $(\mathrm{P})$ 
These equations are included in almost all total stations, allowing measurements and computation to be done almost automatically.

\subsection{Free Station Method}

The Free Station or Spatial Resection positioning is a method to determine an unknown position $\left(\mathrm{X}_{\mathrm{S}}, \mathrm{Y}_{\mathrm{S}}, \mathrm{H}_{\mathrm{S}}\right)$ of a station point, by measuring directions, slope distances and vertical angles with respect to at least two reference points, as indicated in Fig. 5. The procedure involves setting up a total station at a place which has best visibility to all reference and survey points and computing the position and orientation of the instrument by means of the measured data, regarding the reference points.

Since directions, distances and vertical angles are measured to several points, a Free Station positioning can be easily computed applying a Least Square Adjustment, considering the observation equations as following:

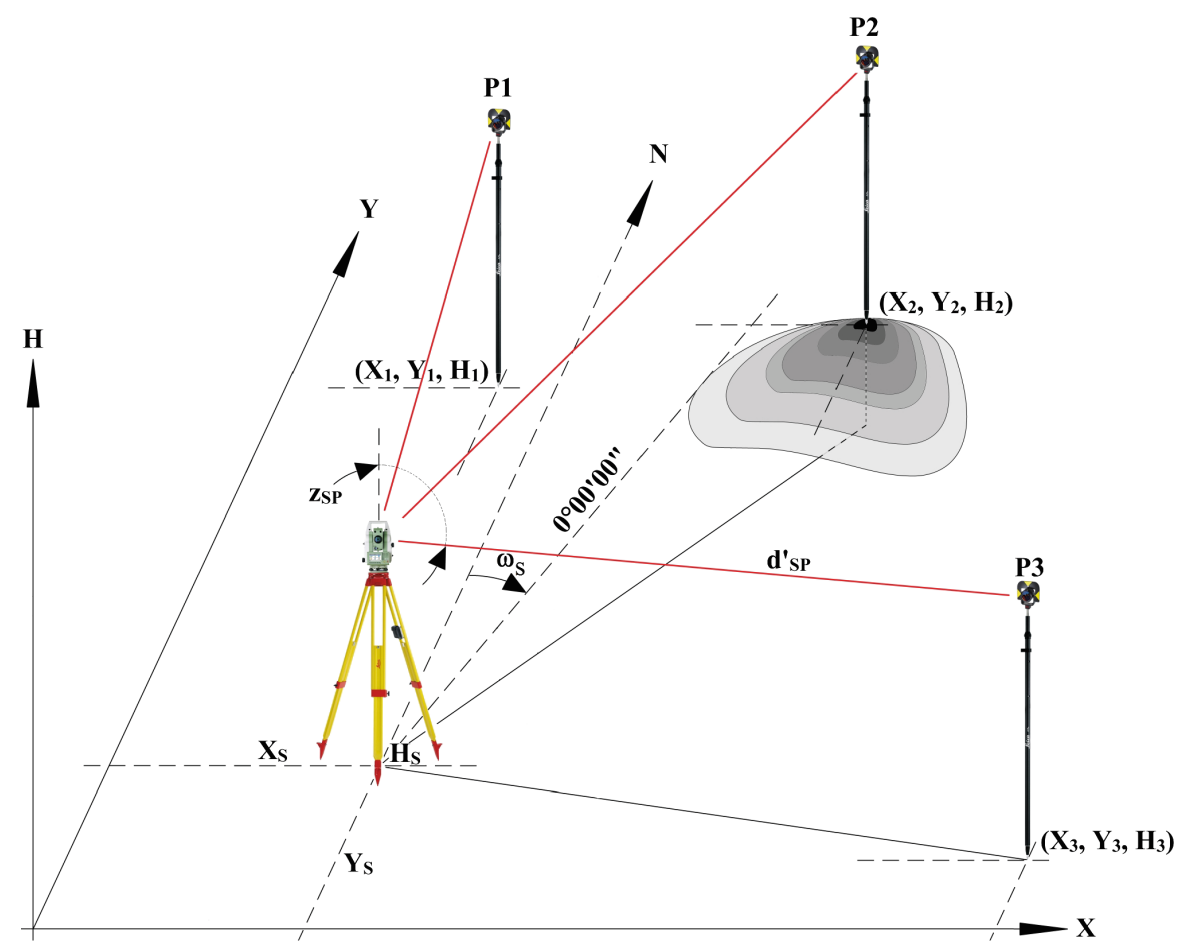

Fig. 5. Free Station method

$$
v \varphi_{S P}=-d \omega_{S}+a^{*} d x_{S}+b^{*} d y_{S}-\left[r_{S P}+\left(\omega_{S}\right)_{0}-\left(\varphi_{S P}\right)_{0}\right]
$$




$$
\begin{gathered}
v d_{S P}=-\operatorname{sen}\left(\varphi_{S P}\right)_{0}{ }^{*} d x_{S}-\cos \left(\varphi_{S P}\right)_{0}{ }^{*} d y_{S}-\left[d_{S P}-\left(d_{S P}\right)_{0}\right] \\
v z_{S P}=\frac{d H_{S}{ }^{*} \operatorname{sen}\left(z_{S P}\right)_{0}}{\left(d_{S P}^{\prime}\right)_{0}}-\left[z_{S P}-\left(z_{S P}\right)_{0}\right]
\end{gathered}
$$

Where,

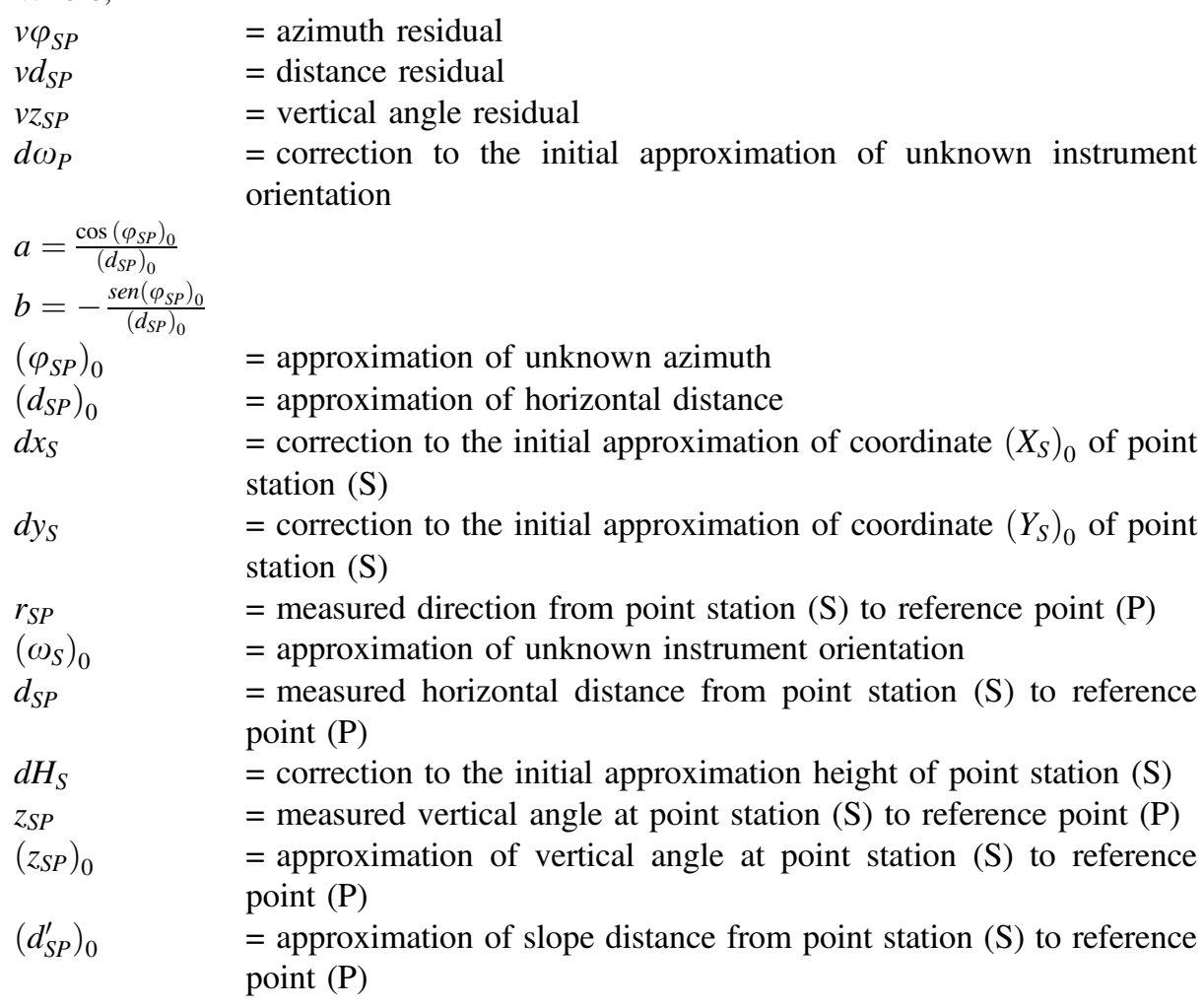

It is important to consider that nearly all modern total stations have in-built software for the free station process that calculates the resulting coordinates and displays the residuals information for the observed lines and coordinates, guiding the user on how to proceed in the field.

\section{Measurement Procedures and Results}

\subsection{GNSS Observation}

To support the building construction, contractor established a topographic control point network, surrounding the building area. The first step in the monitoring measurement procedure was the occupation of all control points of the topography network with GNSS antennas, with satellite tracking time of 10 min, as shown in Fig. 6. 


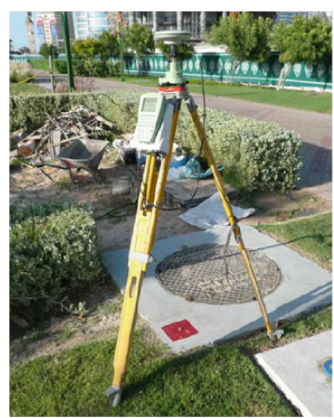

a. Reference Station.

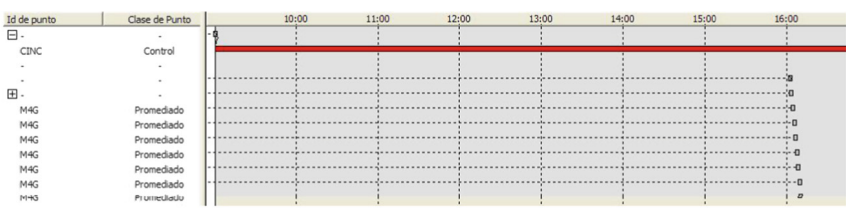

b. Satellite tracking timeline.

Fig. 6. GNSS measurement.

\subsection{Coordinate Transformation for Adequate GNSS Measurement from the Local Coordinates}

For the adequacy of the GNSS measurements with the coordinate system of the building, a coordinate transformation called transformation of two steps was conducted, which consists of a 2D Helmert transformation for the positional coordinates and a plane interpolation for the altitudes. The known coordinates at topographic level were denoted as (X, Y, H). Figure 7 shows the network diagram of the local coordinate system site established by the building contractor. Note that the coordinates determined by the builders do not have any accuracy indication.

Table 3 shows the values of topographic control points and GNSS coordinates.

Table 4 shows the coordinate transformation results.

Table 5 shows coordinate transformation residuals.

Note that the point (M6) was not used in calculating the coordinate transformation as its post-processing residuals, indicated high values compared to other control points. The transformation parameters determined were then inserted in the memory of the GNSS receivers to comply with the topographic building coordinates during monitoring procedures.

\subsection{GNSS Measurement and Polar Measurements}

GNSS observations were performed in the base station receiver (E1), by recording post-processing data and transmitting RTK corrections, and in the GNSS receivers (E2), (E3) and (E4), by recording post-processing data and receiving RTK corrections for real time coordinate computation of each station.

\section{Results}

Conforming to the distinct procedures described above, the outcome of the measurements is presented in Tables 6, 7, 8 and 9. Table 6 shows the coordinates of point (E1), which has been adopted as a base station point for GNSS measurements. Table 7 


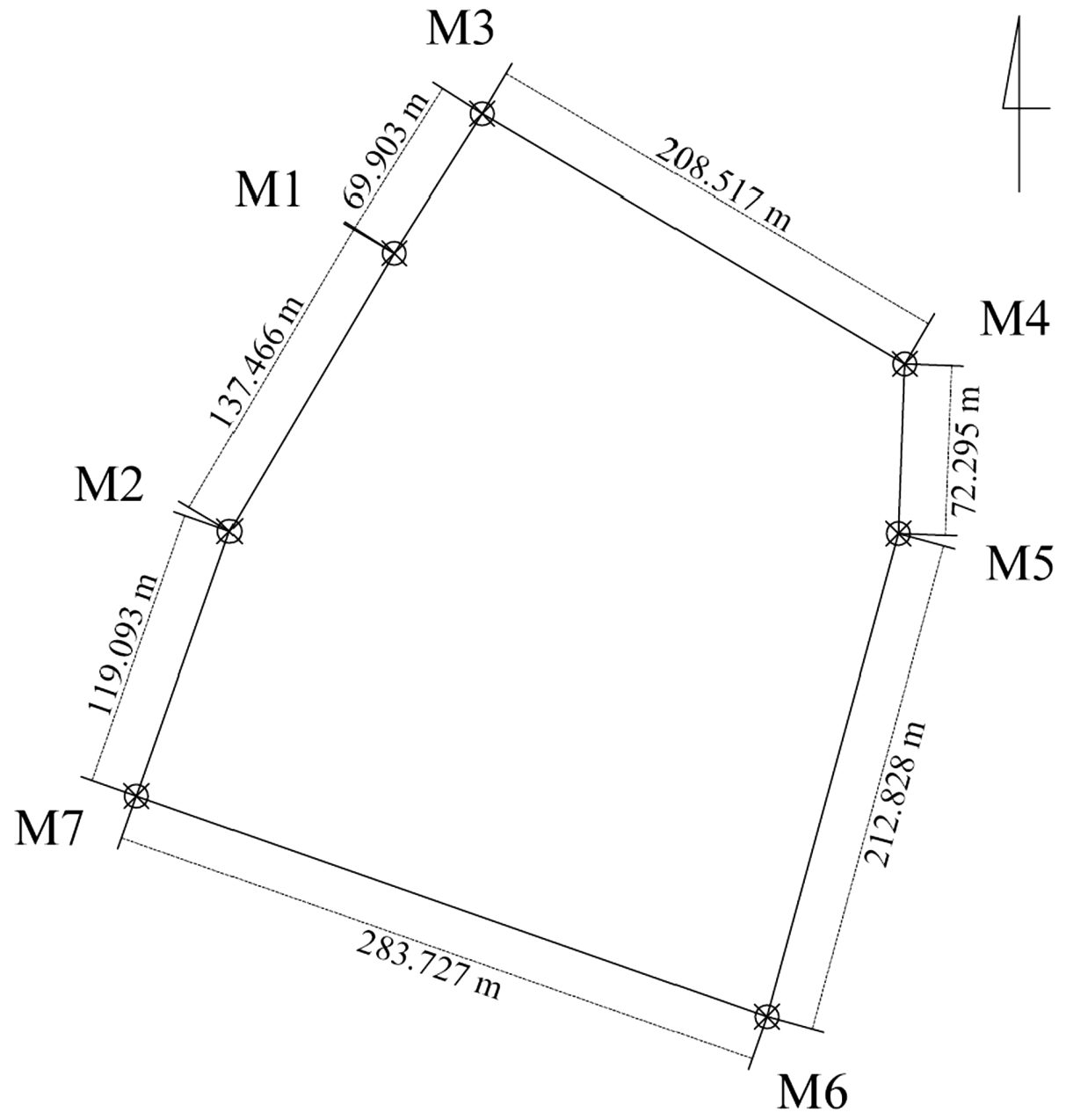

Fig. 7. Diagram of topographic control point network.

Table 3. Topographic control points and WGS84 coordinate values.

\begin{tabular}{l|l|l|l|l|l|l}
\hline $\begin{array}{l}\text { Point } \\
\text { name }\end{array}$ & $\mathrm{X}(\mathrm{m})$ & $\mathrm{Y}(\mathrm{m})$ & $\mathrm{H}(\mathrm{m})$ & Latitude & Longitude & $\begin{array}{l}\text { Ellipsoidal } \\
\text { height } \\
(\mathrm{h})(\mathrm{m})\end{array}$ \\
\hline M1 & 458.345 & 937.665 & 103.236 & $33^{\circ} 24^{\prime} 58.84864^{\prime \prime} \mathrm{S}$ & $70^{\circ} 36^{\prime} 26.03582^{\prime \prime} \mathrm{W}$ & 644.912 \\
\hline M2 & 388.456 & 819.291 & 100.747 & $33^{\circ} 25^{\prime} 02.40038^{\prime \prime} \mathrm{S}$ & $70^{\circ} 36^{\prime} 29.25537^{\prime \prime} \mathrm{W}$ & 642.402 \\
\hline M3 & 495.816 & 996.677 & 104.191 & $33^{\circ} 24^{\prime} 57.08806^{\prime \prime} \mathrm{S}$ & $70^{\circ} 36^{\prime} 24.33003^{\prime \prime} \mathrm{W}$ & 645.859 \\
\hline M4 & 675.313 & 890.564 & 107.192 & $33^{\circ} 25^{\prime} 01.18633^{\prime \prime} \mathrm{S}$ & $70^{\circ} 36^{\prime} 17.90749^{\prime \prime} \mathrm{W}$ & 648.901 \\
\hline M5 & 672.598 & 818.321 & 105.915 & $33^{\circ} 25^{\prime} 03.50512^{\prime \prime} \mathrm{S}$ & $70^{\circ} 36^{\prime} 18.33858^{\prime \prime} \mathrm{W}$ & 647.589 \\
\hline M6 & 612.649 & 612.978 & 102.809 & $33^{\circ} 25^{\prime} 10.55112^{\prime \prime} \mathrm{S}$ & $70^{\circ} 36^{\prime} 21.76643^{\prime \prime} \mathrm{W}$ & 643.005 \\
\hline M7 & 348.935 & 706.947 & 99.097 & $33^{\circ} 25^{\prime} 05.87274^{\prime \prime} \mathrm{S}$ & $70^{\circ} 36^{\prime} 31.28013^{\prime \prime} \mathrm{W}$ & 640.726 \\
\hline
\end{tabular}


Table 4. Coordinate transformation results.

\begin{tabular}{l|l|l|l}
\hline 2D-Helmert transformation & \multicolumn{2}{l}{} \\
\hline Homologous points & 6 & & \\
\hline \multirow{2}{*}{ Rotation origin } & $\mathrm{X} 0$ & & $0.001 \mathrm{~m}$ \\
\cline { 2 - 4 } & $\mathrm{Y} 0$ & $0.000 \mathrm{~m}$ \\
\hline Order & Parameter & Value & $\mathrm{rms}$ \\
\hline 1 & $\mathrm{dX}$ & $861.578 \mathrm{~m}$ & $0.005 \mathrm{~m}$ \\
\hline 2 & $\mathrm{dY}$ & $506.577 \mathrm{~m}$ & $0.005 \mathrm{~m}$ \\
\hline 3 & Rotation & $-6^{\circ} 40^{\prime} 54.85538^{\prime \prime}$ & $0^{\circ} 00^{\prime} 06.13429^{\prime \prime}$ \\
\hline 4 & Scale & $108.2437 \mathrm{ppm}$ & $29.7367 \mathrm{ppm}$ \\
\hline
\end{tabular}

Height transformation

\begin{tabular}{l|l|l|l}
\hline Homologous points & 6 & & \\
\hline Transformation accuracy (mean) & $0.014 \mathrm{~m}$ & & \\
\hline Parameter & -0.00007955 & -0.00014653 & $541.669 \mathrm{~m}$ \\
\hline Height inclination on X & $-0^{\circ} 00^{\prime} 16.40837^{\prime \prime}$ & & \\
\hline Height inclination on Y & $-0^{\circ} 00^{\prime} 30.22398^{\prime \prime}$ & &
\end{tabular}

Table 5. Coordinate transformation residuals.

\begin{tabular}{l|l|l|l|l}
\hline Point & Point type & $\mathrm{dX}(\mathrm{mm})$ & $\mathrm{dY}(\mathrm{mm})$ & $\mathrm{dH}(\mathrm{mm})$ \\
\hline M1 & Position \& Height & 2 & 5 & 7 \\
\hline M2 & Position \& Height & 0 & 5 & 6 \\
\hline M3 & Position \& Height & -12 & 0 & -12 \\
\hline M4 & Position \& Height & 18 & 3 & 15 \\
\hline M5 & Position \& Height & -18 & -11 & -13 \\
\hline M6 & None & - & - & - \\
\hline M7 & Position \& Height & 9 & -3 & -3 \\
\hline
\end{tabular}

Table 6. GNSS base station coordinates.

\begin{tabular}{l|l|l}
\hline $\mathrm{E}(\mathrm{m})$ & $\mathrm{N}(\mathrm{m})$ & $\mathrm{H}(\mathrm{m})$ \\
\hline 458.345 & 937.665 & 103.236 \\
\hline
\end{tabular}

shows the results for point (E4), which was the reference point used for monitoring measurements to points (P1) and (P2). Whereas, Tables 8 and 9 show the results for the monitoring points (P1) and (P2). 
Table 7. Coordinate values of total station (E4).

\begin{tabular}{|c|c|c|c|c|c|c|c|}
\hline Measurement method & $\mathrm{X}(\mathrm{m})$ & $\mathrm{Y}(\mathrm{m})$ & $\mathrm{H}(\mathrm{m})$ & $\begin{array}{l}\Delta \mathrm{X} \\
(\mathrm{mm})\end{array}$ & $\begin{array}{l}\Delta \mathrm{Y} \\
(\mathrm{mm})\end{array}$ & $\begin{array}{l}\Delta \mathrm{H} \\
(\mathrm{mm})\end{array}$ & $\begin{array}{l}\text { Spatial } \\
\text { vector } \\
(\mathrm{mm})\end{array}$ \\
\hline $\begin{array}{l}\text { Method 1: E4 coordinate } \\
\text { values computed by Free } \\
\text { Station positioning method } \\
\text { using ground control points } \\
\text { - considered as true values }\end{array}$ & $\begin{array}{l}510.635 \\
\pm 2.1 \mathrm{~mm}\end{array}$ & $\begin{array}{l}890.502 \\
\pm 2.3 \mathrm{~mm}\end{array}$ & $\begin{array}{l}161.893 \\
\pm 2.7 \mathrm{~mm}\end{array}$ & \multicolumn{4}{|c|}{ Reference point } \\
\hline $\begin{array}{l}\text { Method 2: E4 coordinate } \\
\text { values computed by total } \\
\text { station coupled with GNSS } \\
\text { receiver in post-processing } \\
\text { mode }\end{array}$ & $\begin{array}{l}510.640 \\
\pm 0.8 \mathrm{~mm}\end{array}$ & $\begin{array}{l}890.494 \\
\pm 0.9 \mathrm{~mm}\end{array}$ & $\begin{array}{l}161.869 \\
\pm 1.3 \mathrm{~mm}\end{array}$ & -5 & 8 & 24 & 26 \\
\hline $\begin{array}{l}\text { Method 3: E4 coordinate } \\
\text { values computed by Free } \\
\text { Station method using E2 and } \\
\text { E3 as control points } \\
\text { determined by GNSS RTK } \\
\text { mode }\end{array}$ & $\begin{array}{l}510.644 \\
\pm 3.1 \mathrm{~mm}\end{array}$ & $\begin{array}{l}890.485 \\
\pm 3.5 \mathrm{~mm}\end{array}$ & $\begin{array}{l}161.864 \\
\pm 9.4 \mathrm{~mm}\end{array}$ & -9 & 17 & 29 & 35 \\
\hline
\end{tabular}

Table 8. Coordinate values of monitoring point (P1).

\begin{tabular}{l|l|l|l|l|l|l|l}
\hline Measurement method & $\mathrm{X}(\mathrm{m})$ & $\mathrm{Y}(\mathrm{m})$ & $\mathrm{H}(\mathrm{m})$ & $\begin{array}{l}\Delta \mathrm{X} \\
(\mathrm{mm})\end{array}$ & $\begin{array}{l}\Delta \mathrm{Y} \\
(\mathrm{mm})\end{array}$ & $\begin{array}{l}\Delta \mathrm{H} \\
(\mathrm{mm})\end{array}$ & $\begin{array}{l}\text { Spatial } \\
\text { vector } \\
(\mathrm{mm})\end{array}$ \\
\hline $\begin{array}{l}\text { P1 coordinate values } \\
\text { computed from E4 on }\end{array}$ & $\begin{array}{l}520.808 \\
\pm 2.2 \mathrm{~mm}\end{array}$ & $\begin{array}{l}887.186 \\
\pm 2.4 \mathrm{~mm}\end{array}$ & $\begin{array}{l}161.877 \\
\pm 2.9 \mathrm{~mm}\end{array}$ & \multicolumn{2}{|l}{ Reference point } \\
$\begin{array}{l}\text { Method 1 } \\
\begin{array}{l}\text { P1 coordinate values } \\
\text { computed from E4 on }\end{array}\end{array}$ & $\begin{array}{c}520.811 \\
\pm 1.1 \mathrm{~mm}\end{array}$ & $\begin{array}{c}887.182 \\
\pm 1.1 \mathrm{~mm}\end{array}$ & $\begin{array}{l}161.872 \\
\pm 1.6 \mathrm{~mm}\end{array}$ & -3 & 4 & 5 & 7 \\
$\begin{array}{l}\text { Method 2 } \\
\begin{array}{l}\text { P1 coordinate values } \\
\text { computed from E4 on } \\
\text { Method 3 }\end{array}\end{array}$ & $\begin{array}{c}520.828 \\
\pm 3.2 \mathrm{~mm}\end{array}$ & $\begin{array}{c}887.171 \\
\pm 3.6 \mathrm{~mm}\end{array}$ & $\begin{array}{l}161.861 \\
\pm 9.4 \mathrm{~mm}\end{array}$ & -20 & 15 & 16 & 30 \\
\hline
\end{tabular}

\section{GNSS Coordinate Values Variation of Points (P1) and (P2) Over Around 30 min Time}

Because building construction was in full operation during the test, there were difficulties in performing repetitive testing for the collection of redundant data. Even so, it was possible to install one GNSS antennas at point (P1) to verify the variation of its coordinates, determined by GNSS technology, within a period of approximately $30 \mathrm{~min}$, as presented in Graphics 1 and 2. 
Table 9. Coordinate values of monitoring point (P2).

\begin{tabular}{l|l|l|l|l|l|l|l|l}
\hline Measurement method & $\mathrm{X}(\mathrm{m})$ & $\mathrm{Y}(\mathrm{m})$ & $\mathrm{H}(\mathrm{m})$ & $\begin{array}{l}\Delta \mathrm{X} \\
(\mathrm{mm})\end{array}$ & $\begin{array}{l}\Delta \mathrm{Y} \\
(\mathrm{mm})\end{array}$ & $\begin{array}{l}\Delta \mathrm{H} \\
(\mathrm{mm})\end{array}$ & $\begin{array}{l}\text { Spatial } \\
\text { vector } \\
(\mathrm{mm})\end{array}$ \\
\hline $\begin{array}{l}\text { P1 coordinate values } \\
\text { computed from E4 on } \\
\text { Method 1 }\end{array}$ & $500.802 \pm 2.2 \mathrm{~mm}$ & $896.328 \pm 2.4 \mathrm{~mm}$ & $161.903 \pm 3.0 \mathrm{~mm}$ & \multicolumn{2}{|l|}{ Reference point } \\
\hline $\begin{array}{l}\text { P1 coordinate values } \\
\text { computed from E4 on } \\
\text { Method 2 }\end{array}$ & $500.815 \pm 1.1 \mathrm{~mm}$ & $896.331 \pm 1.1 \mathrm{~mm}$ & $161.892 \pm 1.6 \mathrm{~mm}$ & -13 & -3 & 11 & 17 \\
\hline $\begin{array}{l}\text { P1 coordinate values } \\
\text { computed from E4 on } \\
\text { Method 3 }\end{array}$ & $500.829 \pm 3.3 \mathrm{~mm}$ & $896.322 \pm 3.6 \mathrm{~mm}$ & $161.894 \pm 9.4 \mathrm{~mm}$ & -27 & 6 & 9 & 29 \\
\hline
\end{tabular}

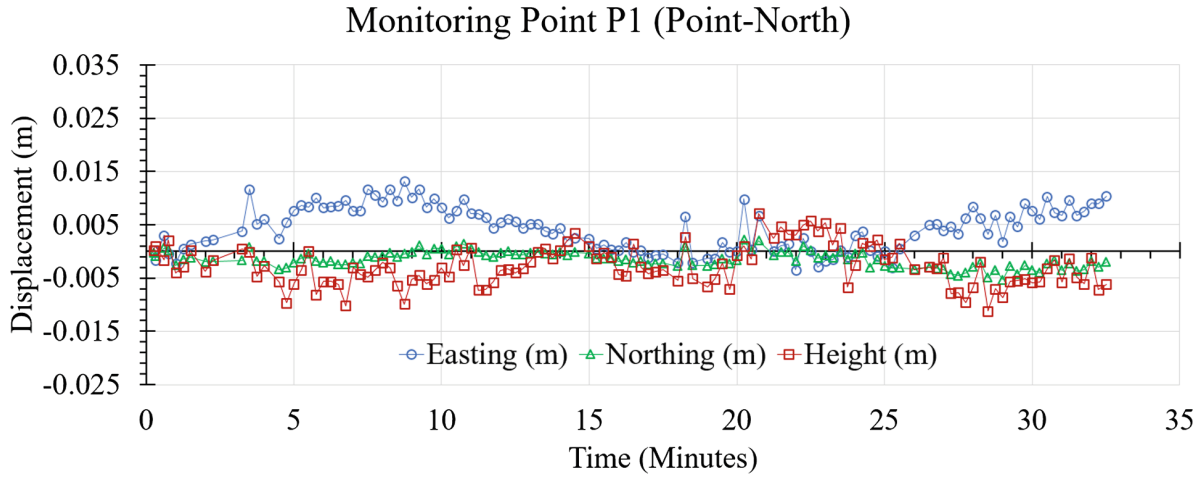

Graphic 1. Coordinate values variation of monitoring point (P1) computed on GNSS post-processing mode.

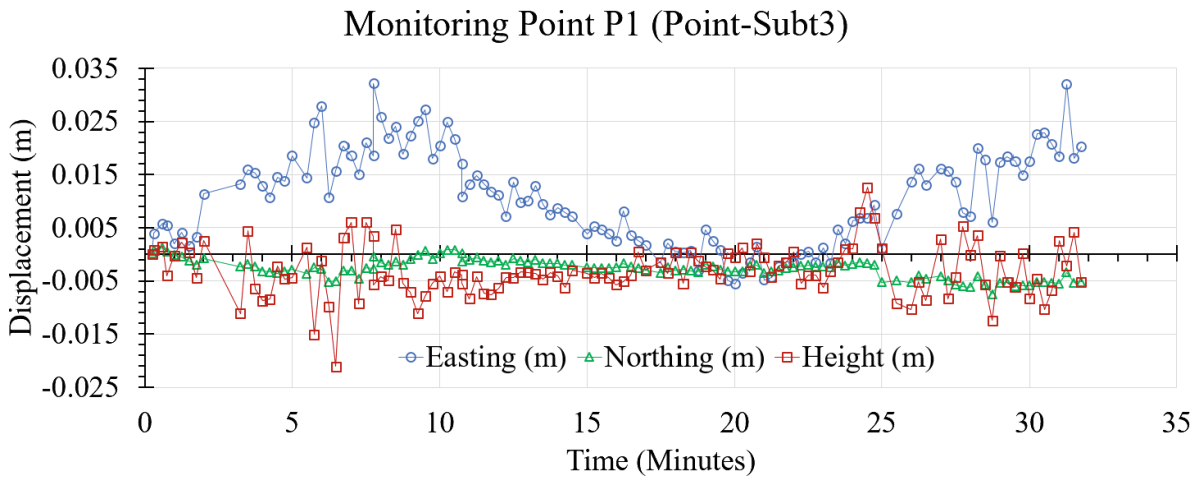

Graphic 2. Coordinate values variation of monitoring point (P1) computed on GNSS RTK mode. 
It is observed that the variations of coordinates obtained in this period are the result of variations inherent by the GNSS technology and due to the movement of the building. The tower was at a height of approximately $60 \mathrm{~m}$ at the time of the test. Graphic 1 represents the variation of the coordinates of monitoring point (P1) on GNSS Post-processing mode, and Graphic 2 represents the variation of the coordinates of monitoring point (P1), on GNSS RTK mode. Indeed, these movements affect the coordinate values of the total station and of the reference prisms installed on the floor of the building. However, as both instruments are anchored in the same structure, they suffer the same displacements, which ensures the effectiveness of measurement methods applied.

\section{Conclusions}

The test showed that the geodetic monitoring methods by means of coupled GNSS receivers with total station, installed on the floor of the building, produce consistent results when compared with the conventional method of measurements, having only one total station installed on the floor of the building and control points on the ground. The variations found in comparisons of the results are due to the deterioration of the accuracy of GNSS measurements itself.

As expected, and according to Table 7, the differences between the coordinates of measuring point (E4), determined by GNSS measurements in post processing mode and the coordinates of the same point determined by Free Station positioning method, are smaller than the coordinates of point (E4), determined through Free Station positioning method based on control points with coordinates determined through GNSS measurements in RTK mode. The same tendency of accuracy variation is verified in Tables 8 and 9 for the monitoring points (P1) and (P2). Although the sample is restricted, the results indicate that, for the particular situation of this test, the positioning method based on GNSS measurements in post-processing produces acceptable values for this kind of geodetic monitoring. Furthermore, the results obtained with GNSS measurements in RTK mode, indicate that the proposed measurement method requires further research to assess its suitability for this kind of geodetic monitoring.

It is important to emphasize that the work presented in this paper is the result of a single test, with little measurement redundancy. The authors consider that its scientific value lies in the fact that it was carried out in practical work conditions, still allowing interesting measurements to be properly taken.

Acknowledgments. This work was carried out by the help of many supporters, which we appreciate enormously.

\section{References}

Afeni, T.B., Cawood, F.T.: Slope monitoring using total station: what are the challenges and how should these be mitigated? South Afr. J. Geomat. 2(1), 41-53 (2013) 
Bird, B.: Analysis of survey point displacement using total station measurements. A Technical report, Geomatics Engineering Department of British Columbia Institute of Technology, England (2009)

Baykal, O., Tari, E., Coşkun, M., Erden, T.: Accuracy of point layout with polar coordinates. J. Surv. Eng. 131(3), 87-93 (2005). USA

Erol, B.: Evaluation of high-precision sensors in structural monitoring. Sensors 10, 10803-10827 (2010). doi:10.3390/s101210803. www.mdpi.com/journal/sensors

Erol, S., Erol, B., Ayan, T.: A general review of the deformation monitoring techniques and a case study: analyzing deformations using GPS/levelling. Civil Engineering Faculty, Geodesy Division, International Society for Photogrammetry and Remote Sensing, Commission VII, WG VII/5. Istanbul Technical University, Istanbul, Turkey (2004)

Leica Geosystems: Controlling vertical towers in the global magazine of leica geosystems. Reporter no. 30, p. 31. http://w3.leica-geosystems.com/media/new/product_solution/Leica_ Geosystems_TruStory_Controlling_Vertical_Towers.pdf

Mascarenhas, Q.G, Silva, I.: Shell dam horizontal displacement monitoring - comparative study using geodetic measurement, optical plumb and GPS technologies. J. Appl. Geodesy 3, 249255 (2009). 6 de Gruyter, Germany

US Army Corps of Engineers: Structural Deformation Surveying, 292 p. Department of the Army, Washington, USA (2002)

Van Cranembroeck, J.: State of the art in structural geodetic monitoring solutions for hydro power plant. FIG Working Week 2011, Marrakech, Morocco (2011)

Yi, T.-H., Li, H.-N., Gu, M.: Recent research and applications of GPS-based monitoring technology for high-rise structures. Structural control and health monitoring, Published Online in Wiley Online Library (2012). (wileyonlinelibrary.com) 